Volume 2, Nomor 1, April 2021, hlm 34-42

JTTM: Jurnal Terapan Teknik Mesin

p ISSN 2721-5377| e ISSN 2721-7825

\title{
PERENCANAAN SISTEM PENDINGIN UDARA MENGGUNAKAN CEILING DUCT DENGAN PENGATURAN SISTEM VRV/F PADA GEDUNG PERKANTORAN 3 LANTAI
}

\section{AIR COOLING SYSTEM PLANNING USING CEILING DUCT WITH VRV/F SYSTEM SETTINGS IN 3 FLOOR OFFICE BUILDING}

\author{
Srihanto $^{1}$, Moch.Sugiri ${ }^{2 *}$ \\ $1^{*, 2}$ Program Studi Teknik Mesin, Institut Teknologi Budi Utomo Jakarta \\ ${ }^{1 * 2}, 2 J 1$. Mawar Merah No.23, RT.2/RW.1, Pd. Kopi, Kec. Duren Sawit, Kota Jakarta Timur 13460 \\ *Koresponden Email: sugiri.moch@gmail.com
}

\begin{abstract}
Abstrak. Di negara tropis menjadikan kebutuhan akan sistem pengkondisian udara khususnya untuk gedunggedung bertingkat supaya memberi kenyamanan bagi penghuninya. Untuk itu, diperlukan perencanaan sistem pengkondisian udara menggunakan ceiling duct dengan pengaturan sistem VRV/F (Variable Refrigerant Volume/FLOW) supaya beban dan kapasitasnya sesuai dan lebih efisien. Dalam menghitung beban pendingin mulai dari beban sensibel dan beban, dan perhitungan ukuran ducting. Metode penelitian yang digunakan untuk melakukan perencanaan sistem pengkondisian udara menggunakan ceiling duct dengan pengaturan sistem VRV/F adalah dengan metode observasi dengan mengambil data yang dibutuhkan. Melakukan perhitungan dan analisis dengan data - data yang diperoleh. Sehingga setelah melakukan perencanaan didapatkan total beban lantai $5=270,752.79 \mathrm{Btu} / \mathrm{hr}(79.3498 \mathrm{~kW})$, lantai $6=280,568.37 \mathrm{Btu} / \mathrm{hr}(82.227 \mathrm{~kW})$, dan lantai $7=229,690.66$ Btu/hr $(67.3157 \mathrm{~kW})$. Ukuran ducting supply yang dipakai adalah: Tinggi $=75 \mathrm{~mm}-450 \mathrm{~mm}$, Lebar $=75 \mathrm{~mm}-$ $450 \mathrm{~mm}$ dan ukuran ducting return yang dipakai adalah Tinggi $=75 \mathrm{~mm}-450 \mathrm{~mm}$, Lebar $=75 \mathrm{~mm}-450 \mathrm{~mm}$. Dari hasil perencanaan di tentukan sistem pengkondisian udara menggunakan sistem ceiling duct dengan pengaturan sistem VRV/VRF. Keunggulannya adalah Easy to Maintenance, memiliki kehandalan tinggi, bisa digunakan kapasitas besar, space saving desain, berbeda unit indoor dalam satu sistem, dan menggunakan refrigerant type R410.
\end{abstract}

Kata Kunci: Beban pendingin, Design Ducting, Pengkondisian Udara, Kenyamanan, ceiling ducting.

\begin{abstract}
In tropical countries, there is a need for air conditioning systems, especially for high-rise buildings to provide comfort for their residents. For this reason, it is necessary to plan an air conditioning system using a ceiling duct with a VRV / F (Variable Refrigerant Volume / FLOW) system setting so that the load and capacity are appropriate and more efficient. In calculating the cooling load, starting from the sensible load and the load, and calculating the size of the ducting. The research method used to plan an air conditioning system using a ceiling duct with VRV / F system settings is the observation method by taking the required data. Perform calculations and analysis with the data obtained. So that after planning the total load on the 5th floor = $270,752.79 \mathrm{Btu} / \mathrm{hr}(79.3498 \mathrm{~kW})$, the 6th floor $=280,568.37 \mathrm{Btu} / \mathrm{hr}(82,227 \mathrm{~kW})$, and the 7 th floor $=$ $229,690.66 \mathrm{Btu} / \mathrm{hr}(67.3157 \mathrm{~kW})$. The size of the ducting supply used is: Height $=75 \mathrm{~mm}-450 \mathrm{~mm}$, Width $=75 \mathrm{~mm}$ - 450mm and the size of the ducting return used is Height $=75 \mathrm{~mm}-450 \mathrm{~mm}$, Width $=75 \mathrm{~mm}-450 \mathrm{~mm}$. From the planning results, it is determined that the air conditioning system uses a ceiling duct system with VRV / VRF system settings. The advantages are Easy Maintenance, high reliability, large capacity use, space-saving design, different indoor units in one system, and using R410 type refrigerant.
\end{abstract}

Keywords: cooling load, Design Ducting, Air Conditioning, Comfort, ceiling ducting.

\section{PENDAhUluan}

Berada pada bagian negara tropis menjadikan kebutuhan akan sistem pengkondisian udara bagi bangunan-bangunan di Jakarta sebagai salah satu prioritas utama [1]. Sistem udara yang meliputi

JTTM: Jurnal Terapan Teknik Mesin is licensed under a Creative Commons Attribution-NonCommercial 4.0 International License. 
pendinginan dalam suatu ruangan serta pengaturan suhu kelembaban untuk meningkatkan kualitas udara yang dibutuhkan.

Agar sistem pengkondisian udara bekerja secara efisien di semua ruangan dalam satu bangunan diperlukan perhitungan beban pendingin dan dilanjutkan dengan perencanaan sistem pengkondisian udara untuk bangunan. Ada dua faktor yang dapat mempengaruhi beban pendingin, yaitu dari dalam ruangan (internal heat gain) seperti penghuni ruangan, lampu dan peralatan yang menghasilkan kalor, kedua adalah faktor dari luar (external heat gain) meliputi konduksi pada dinding, atap, lantai, dan radiasi matahari[2].

Pendinginan udara untuk menghasilkan temperatur ruangan ideal, kemudian suhu ruangan mulai dari kelembaban relatif, kecepatan rambat udara, kebersihan udara, serta sirkulasi udara di dalam ruangan tersebut, untuk menghasilkan ruangan yang nyaman[3]. Analisis perubahan kondisi dalam ruangan antar musim yang ditempatkan di sekitar pelataran tengah untuk mendapatkan jumlah perolehan matahari yang optimal[4].

Tujuan dari penelitian ini untuk menghitung kebutuhan sistem pendingin dalam gedung, agar efisiensi dalam penggunaan daya listrik.

\section{METODE}

Berikut ini adalah langkah-langkah yang dilakukan dalam penelitian.
a. Studi kepustakaan dan observasi
b. Pengumpulan data
c. Analisa pengolahan data
d. Tahapan perencanaan
e. Kesimpulan

2.1 Analisis data.

Perancangan Gedung XZX, Jalan Soepomo, Jakarta selatan, yang berjumlah 8 lantai dan ruangan yang akan dikondisikan berjumlah 3 lantai yaitu di lantai 5, 6, dan 7 .

\section{A. Tempat dan Waktu Penelitian}

Tempat penulis melakukan penelitian adalah di Gedung XZX, Jl. Soepomo no.27 Tebet, Jakarta Selatan. Lokasi gedung ini berada di Jakarta selatan dengan titik koordinat $6^{\circ} \mathrm{LS}$ dan $106^{\circ} \mathrm{BT}$, arah bangunan menghadap barat. Waktu penelitian dimulai 01 April-30 Juni 2020.

B. Jenis Keterangan Bangunan

Dari data yang didapatkan dari ASHRAE. Handbook, Fundamental, P-1 Edition, Atlanta, 2017. Bab 14, Apendik, cuaca kota Jakarta pada tabel 1. 
Perencanaan Sistem Pendingin Udara Menggunakan Ceiling Duct Dengan Pengaturan Sistem

Vrv/F Pada Gedung Perkantoran 3 Lantai

Tabel 1. Kondisi udara di Jakarta

\begin{tabular}{ll}
\hline \multicolumn{1}{c}{ TINJAUAN } & \multicolumn{1}{c}{ NILAI } \\
\hline Latitude (Garis Lintang) & $6^{\circ} \mathrm{LS}$ \\
Design Dry-Bulb $(1 \%)$ & $93.6^{\circ} \mathrm{F} / 34.2{ }^{\circ} \mathrm{C}$ \\
Design Wet-Bulb $(1 \%)$ & $78.8^{\circ} \mathrm{F} / 26^{\circ} \mathrm{C}$ \\
Humidity Ratio $(\mathrm{W})$ & $65 \%$ \\
Relative Humidity & $65 \%$ \\
\hline
\end{tabular}

Berikut ini data kondisi udara rancangan dari sumber yang sama:

Tabel 2. Kondisi udara rancangan

\begin{tabular}{l|c}
\hline \multicolumn{1}{c|}{ TINJAUAN } & NILAI \\
\hline Latitude (Garis Lintang) & $6.12^{\circ} \mathrm{LS}$ \\
Design Dry-Bulb Temp. Room $(\mathrm{Tr})$ & $77^{\circ} \mathrm{F} / 25^{\circ} \mathrm{C}$ \\
Design Wet-Bulb Temp. Room & $66.9^{\circ} \mathrm{F} / 19.4^{\circ} \mathrm{C}$ \\
Humidity Ratio Design (W) & $0.009 \mathrm{lb} / \mathrm{lb}$ \\
Relative Humidity & $50 \pm 5 \%$ \\
Bulan Terpanas (Rancangan) & $\mathrm{MAY}$ \\
Jam Terpanas & 15.00 \\
\hline
\end{tabular}

\section{HASIL DAN PEMBAHASAN.}

3.1 Perhitungan beban pendingin.

\subsubsection{Beban eksternal.}

Beban pendinginan eksternal bersumber dari beban kalor [5][6].

A. Pancaran sinar matahari akan mempengaruhi terhadap pendingin dengan perhitungan beban kalor.

$Q=U \times A \times C L T D_{\text {corr }}$

$C L T D_{c o r r}=(C L T D+L M) \times K+(78-T r)+(T o-85)$

Dimana:

$\mathrm{Q}=$ Kalor dari dinding partisi (Btu/hr).

$\mathrm{U}=$ Koefisien perpindahan kalor $\left(\mathrm{Btu} / \mathrm{hr} . \mathrm{ft} 2{ }^{\circ} \mathrm{F}\right)$.

$\mathrm{A}=$ Luas dinding $(\mathrm{ft} 2)$.

$\mathrm{CLTD}_{\text {corr }}=$ Cooling Load Temperature Difference Corrected $\left({ }^{\circ} \mathrm{F}\right)$.

LM = Nilai koreksi Latitude and month ().

$K=$ Faktor warna, $K=1$ warna gelap; $K=0,83$, warna menengah; $K=0,63$, warna terang.

$\operatorname{Tr}=$ Suhu ruang perencanaan $\left({ }^{\circ} \mathrm{F}\right)$.

To $=$ Suhu udara luar $\left({ }^{\circ} \mathrm{F}\right)$. 
B. Beban kalor yang ditimbulkan oleh dinding secara konduksi dan partisi[5][6].

$Q=U \times A \times T D$

Dimana:

$\mathrm{TD}=$ Beda temperatur setiap ruangan.

C. Beban kalor melalui atap[7][5].

$Q=U \times A \times C L T D_{\text {corr }}$

$C L T D_{\text {corr }}=(C L T D+L M) \times K+(78-T r)+(T o-85) \times f(2.20)$

Dimana:

$f=$ Faktor Attic (hanya untuk atap).

D. Beban kalor pada kaca partisi [7].

$Q=U \times A \times C L T D_{\text {corr }}$

E. Beban radiasi pancaran sinar matahari pada kaca[7].

$Q=S H G F \times A \times S C \times C L F$

Dimana:

$\mathrm{SHGF}=$ Solar heat gain factor $\left({ }^{\circ} \mathrm{F}\right)[8]$.

$\mathrm{SC}=$ Shading Coefficient [8].

CLF $=$ Cooling Load Factor untuk kaca [8].

F. Beban kalor melalui lantai.

$Q=U \times A \times T D$

Dimana:

$\mathrm{TD}=$ Beda temperatur tanah dengan ruangan yang dikondisikan $\left(\mathrm{ft}^{2}\right)$.

G. Beban kalor melalui partisi.

$Q=U \times A \times T D$

Dimana:

$\mathrm{TD}=$ Beda suhu antara ruangan yang dikondisikan dengan ruangan yang bersebelahan $\left(\mathrm{ft}^{2}\right)$.

\subsubsection{Beban internal.}

Beban pendinginan internal bersumber dari beban kalor [5].

A. Beban kalor oleh faktor manusia.

$Q=(q s / p \times n \times C L F)+q l / p \times n)$

Dimana:

$\mathrm{qs} / \mathrm{p}=$ Beban sensibel yang dihasilkan setiap orang per jam (Btu/hr) [5](ASHRAE GRP 158 cooling load and Heating Load Calculation Manual,Table 4.5).

$\mathrm{N}=$ Jumah orang.

B. Beban kalor yang ditimbulkan oleh peralatan.

$Q=(C s \times q t s \times C L F)+C 1 \times q t l)$ 
Perencanaan Sistem Pendingin Udara Menggunakan Ceiling Duct Dengan Pengaturan Sistem

Vrv/F Pada Gedung Perkantoran 3 Lantai

Dimana:

Cs = Coefficient Sensible[5] (ASHRAE GRP 158 CoolingLoad and Heating Load Calculation Manual, Tabel 1)

$\mathrm{Qt}=$ Manufacturer's Input Ranting

C. Beban kalor yang diperoleh dari penerangan [9]

$$
Q=3,4 \times \text { qinput } \times F u \times C L F
$$

Dimana:

3,4= Faktor pengali konversi satuan Watt ke Btu/hr

$\mathrm{q}_{\text {inpu }}=$ Daya total dari lampu

$\mathrm{Fu}=$ Faktor dari lampu yang menyala $(\mathrm{Fu}=1$ karena seluruh lampu menyala).

\subsubsection{Beban ventilasi dan infiltrasi.}

A. Beban ventilasi merupakan beban kalor yang berasal dari udara luar dimanfaatkan sebagai udara ventilasi, terdiri dari beban sensibel dan laten [5].

B. Beban Infiltrasi berasal dari masuknya udara luar tanpa ke dalam ruangan yang dikondisikan, yang dikarenakan gaya-gaya alamiah (tekanan dalam ruangan lebih kecil dibanding dengan tekanan di luar lingkungan). Terdapat dua macam beban infiltrasi itu beban infiltrasi melalui pintu dan jendela[5].

\subsubsection{Beban total ruangan[7].}

Beban ruangan yang didapatkan terdiri atas beban kalor sensibel ruangan (RSHG) dan beban laten ruangan (RLHG) yang masing masing didapat dari penjumlahan total beban internal dan beban eksternal [7].

a. Beban sensibel ruangan terdiri [6].

RSHG = Kalor dinding + kalor ceiling + kalor lantai + kalor kaca partisi + kalor pintu partisi + kalor sensibel penghuni + kalor penerangan + kalor sensibel peralatan + kalor sensibel infiltrasi.

b. Beban laten ruangan terdiri [6].

$R L H G=$ Kalor laten orang + Kalor laten peralatan + Kalor latern infiltrasi

c. Beban Total Ruangan [6].

$R T H G=R S H G+R L H G$

Dimana:

RTHG = Beban total ruangan (Watt).

RSHG = Beban sensibel ruangan (Watt).

RLHG = Beban laten ruangan (Watt). 
3.2 Perhitungan ducting dengan duct sizer MCQUAY.

Dalam melakukan perhitungan ukuran ducting menggunakan program Duct Sizer MCQUAY harus mengetahui data-data yang diperlukan [10].

- Air Flow Rate (cfm)

- Head Loas.

Tabel 1. Perhitungan ducting pada zone $1,2 \& 3$.

\begin{tabular}{|c|c|c|c|c|c|c|c|}
\hline zone & Section & debit & $1($ In) & V (fpm) & D & $\begin{array}{l}\text { Pv } \\
\text { (in.WC) }\end{array}$ & $\begin{array}{l}\text { HXW } \\
\text { (In) }\end{array}$ \\
\hline \multirow{17}{*}{1} & A-B & 280 & 188,98 & 745,2 & 8,18 & 0,0368 & $8 \times 8$ \\
\hline & B-D & 511 & 137,8 & 866,1 & 10,37 & 0,0474 & $10 \times 10$ \\
\hline & C-D & 231 & 98,43 & 710 & 7,65 & 0,0326 & $7 \times 7$ \\
\hline & D-E & 742 & 110,24 & 950 & 12,02 & 0,0552 & $11 \times 11$ \\
\hline & F-G & 309 & 188,98 & 763,9 & 8,75 & 0,0342 & $8 \times 8$ \\
\hline & G-E & 540 & 137,8 & 878 & 10,37 & 0,0529 & $10 \times 10$ \\
\hline & H-E & 231 & 98,43 & 710 & 7,65 & 0,0326 & $7 \times 7$ \\
\hline & E-I & 1513 & 157,48 & 1132 & 15,84 & 0,0762 & $15 \times 15$ \\
\hline & $\mathrm{J}-\mathrm{K}$ & 309 & 188,98 & 763,9 & 8,75 & 0,0342 & $8 \times 8$ \\
\hline & K-I & 540 & 137,8 & 878 & 10,37 & 0,0529 & $10 \times 10$ \\
\hline & I-L & 2053 & 31,5 & 1219,6 & 17,49 & 0,0943 & $16 \times 16$ \\
\hline & $\mathrm{M}-\mathrm{O}$ & 231 & 39,37 & 710 & 7,65 & 0,0326 & $7 \times 7$ \\
\hline & $\mathrm{N}-\mathrm{O}$ & 22 & 118,11 & 387,4 & 3,28 & 0,0088 & $3 \times 3$ \\
\hline & O-L & 253 & 98,43 & 726,5 & 8,18 & 0,03 & $8 \times 8$ \\
\hline & L-P & 2306 & 78,74 & 1254,6 & 18,58 & 0,0934 & $17 \times 17$ \\
\hline & Q-P & 200 & 165,35 & 684,7 & 7,08 & 0,0334 & $7 \times 7$ \\
\hline & P-R & 2506 & 98,43 & 1280,2 & 19,12 & 0,0984 & $18 \times 18$ \\
\hline \multirow{12}{*}{2} & $A-C$ & 409 & 98,43 & 0,0374 & 819,3 & 9,84 & $9 \times 9$ \\
\hline & B-C & 409 & 43,31 & 0,0374 & 819,3 & 9,84 & $9 \times 9$ \\
\hline & C-D & 818 & 145,67 & 973,2 & 12,56 & 0,0564 & $12 \times 12$ \\
\hline & E-D & 278 & 51,18 & 743,9 & 8,18 & 0,0362 & $8 \times 8$ \\
\hline & F-D & 278 & 51,18 & 743,9 & 8,18 & 0,0362 & $8 \times 8$ \\
\hline & D-G & 1374 & 141,73 & 1105,6 & 15,3 & 0,0721 & $14 \times 14$ \\
\hline & $\mathrm{H}-\mathrm{G}$ & 283 & 39,37 & 747,2 & 8,18 & 0,0375 & $8 \times 8$ \\
\hline & $\mathrm{I}-\mathrm{G}$ & 283 & 66,93 & 747,2 & 8,18 & 0,0375 & $8 \times 8$ \\
\hline & G-J & 1940 & 145,67 & 1202,9 & 16,93 & 0,0959 & $16 \times 16$ \\
\hline & K-J & 283 & 39,37 & 747,2 & 8,18 & 0,0375 & $8 \times 8$ \\
\hline & L-J & 283 & 66,93 & 747,2 & 8,18 & 0,0375 & $8 \times 8$ \\
\hline & L-M & 2506 & 19,69 & 1280,2 & 19,12 & 0,0984 & $18 \times 18$ \\
\hline \multirow{4}{*}{3} & A-B & 11 & 129,92 & 322,1 & 2,66 & 0,005 & $3 \times 3$ \\
\hline & B-E & 22 & 70,87 & 387,4 & 3,28 & 0,0097 & $3 \times 3$ \\
\hline & C-E & 77 & 125,98 & 536,9 & 4,88 & 0,0219 & $5 \times 5$ \\
\hline & D-E & 11 & 90,55 & 322,1 & 2,66 & 0,005 & $3 \times 3$ \\
\hline
\end{tabular}


Perencanaan Sistem Pendingin Udara Menggunakan Ceiling Duct Dengan Pengaturan Sistem

Vrv/F Pada Gedung Perkantoran 3 Lantai

\begin{tabular}{lllllll} 
E-F & 110 & 90,55 & 588,2 & 5,98 & 0,0198 & $6 \times 6$ \\
F-H & 123 & 125,98 & 605,2 & 5,98 & 0,0248 & $6 \times 6$ \\
G-H & 25 & 39,37 & 350 & 2,66 & 0,0094 & $3 \times 3$ \\
H-I & 138 & 118,11 & 623,2 & 6,56 & 0,0216 & $6 \times 6$ \\
J-I & 228 & 70,87 & 707,7 & 7,65 & 0,031 & $7 \times 7$ \\
K-L & 228 & 106,3 & 707,7 & 7,65 & 0,031 & $7 \times 7$ \\
L-I & 456 & 39,37 & 841,9 & 9,84 & 0,0465 & $9 \times 9$ \\
I-M & 822 & 141,73 & 974,3 & 12,56 & 0,057 & $12 \times 12$ \\
N-O & 11 & 118,11 & 322,1 & 2,66 & 0,005 & $3 \times 3$ \\
O-M & 239 & 70,87 & 716,1 & 7,65 & 0,0349 & $7 \times 7$ \\
P-Q & 228 & 106,3 & 707,7 & 7,65 & 0,031 & $7 \times 7$ \\
Q-M & 456 & 39,37 & 841,9 & 9,84 & 0,0465 & $9 \times 9$ \\
M-R & 1517 & 118,11 & 1132,7 & 15,84 & 0,0766 & $15 \times 15$ \\
S-T & 307 & 157,48 & 762,6 & 8,75 & 0,0338 & $8 \times 8$ \\
T-R & 535 & 70,87 & 876 & 10,37 & 0,0519 & $10 \times 10$ \\
U-V & 228 & 106,3 & 707,7 & 7,65 & 0,031 & $7 \times 7$ \\
V-R & 456 & 39,37 & 841,9 & 9,84 & 0,0465 & $9 \times 9$ \\
R-W & 2508 & 39,37 & 1200,5 & 19,12 & 0,0986 & $18 \times 18$ \\
\hline
\end{tabular}

\subsection{Keunggulan AC VRV dari AC biasa.}

Untuk keunggulan AC VRV dibandingkan dengan AC SPLIT biasa yaitu:

a. Easy to Maintenance.

Semua control kerja compressor, PCB dan EXF/EEV, dapat dilakukan pada Mainboard pada outdoor. Sehingga mempermudah dan lebih sederhana untuk melakukan analisis.

b. Memiliki kehandalan yang tinggi.

c. Bisa digunakan untuk kapasitas yang besar.

d. Space Saving Design.

Penempatan outdoor yang tidak membutuhkan ruang yang luas, dan lebih mudah untuk di tempatkan di atas gedung karena tidak memiliki bobot yang terlalu berat dibandingkan chiller.

e. Berbeda unit indoor dalam satu sistem.

Untuk pemilihan indoor indoor yang bervariasi dalam satu sistem menjadikan ac VRV/VRF lebih mudah saat melakukan desain kebutuhan satu bangunan. Indoor bisa dipilih sesuai kebutuhan ruangan.

f. Refrigerant type R410.

Refrigerant yang sangat ramah lingkungan dan tidak merusak lapisan ozone.

Pada tabel 2 dijelaskan perhitungan rasio AC per ft2, dimana setiap ruangan yang dihitung pada lantai 5, didapat nilai sesuai dengan kebutuhan. 
Tabel 2. Perhitungan Rasio AC per ft2

\begin{tabular}{lllll}
\hline \multirow{2}{*}{ LANTAI } & \multicolumn{1}{c}{ RTHG } & \multicolumn{1}{c}{$\begin{array}{c}\text { LUAS } \\
\text { /RUANGAN }\end{array}$} & $\begin{array}{c}\text { Rasio kebutuhan } \\
\text { AC/Ft2 }\end{array}$ \\
\cline { 3 - 5 } & & \multicolumn{1}{c}{ Btu/hr } & \multicolumn{1}{c}{ Ft2 } & \multicolumn{1}{c}{ Btu/sq.ft } \\
\hline \multirow{2}{*}{ Finance manager room } & 10069,24 & 163,6 & 61,55 \\
library & 22258,62 & 279,9 & 79,52 \\
finance \& purchasing div. & 49879,32 & 1193,7 & 41,79 \\
doc storage & 7193,33 & 178,7 & 40,25 \\
copy \& printer & 779,9 & 71 & 10,98 \\
storage & 464,62 & 119,5 & 3,89 \\
meeting room 51 & 30333,58 & 290,6 & 104,38 \\
meeting room 52 & 20658,06 & 194,8 & 106,05 \\
open meeting area & 42023,41 & 387,5 & 108,45 \\
reception lobby & 71627,65 & 864,3 & 82,87 \\
guest room & 10759,31 & 149,6 & 71,92 \\
Locket & 516,7 & 79,7 & 6,48 \\
Half lift & 1496,91 & 398,3 & 3,76 \\
ac/electric room & 2692,14 & 75,3 & 35,75 \\
\hline
\end{tabular}

\section{SIMPULAN}

Dari perhitungan dan pembahasan yang sudah dilakukan, maka dapat ditarik beberapa kesimpulan mengenai hasil analisis "Perencanaan Sistem Pendingin Udara Menggunakan Ceiling Duct Dengan Pengaturan Sistem Vrv Pada Gedung Perkantoran 3 Lantai Di Jakarta” yaitu sebagai berikut: Jumlah total beban pada ruangan lantai 5 adalah sebesar 270,752.79 Btu/hr atau $79.3498 \mathrm{~kW}$, untuk jumlah total beban pada ruangan lantai 6 adalah sebesar 280,568.37 Btu/hr atau $82.227 \mathrm{~kW}$, dan untuk jumlah total beban pada ruangan lantai 7 adalah sebesar 229,690.66 Btu/hr atau $67.3157 \mathrm{~kW}$. Desain Ducting Supply yang dipakai adalah: Tinggi: $75 \mathrm{~mm}-450 \mathrm{~mm}$ dan untuk Lebar: $75 \mathrm{~mm}-450 \mathrm{~mm}$. Untuk desain Ducting Return yang dipakai adalah: Tinggi 75mm-450mm. Menurut penelitian penulis banyak sekali keunggulan yang ditemukan di AC sistem VRV ini dibanding dengan AC split biasa yaitu dari segi daya sistem VRV ini sangat menghemat daya dibanding AC split biasa, dan dari segi tempat Vrv ini tidak boros untuk tempat karena 1 Outdoor dapat digunakan untuk beberapa unit indoor.

\section{REFERENSI}

[1] P. Pengguna, B. Gedung, and H. Jakarta, "VOL. 2 SISTEM PENGKONDISIAN UDARA \& VENTILASI-IFCGuideVol2-IND-edit," vol. 2, no. 38, 2012.

[2] A. Kurniawati and G. Doloksaribu, "Tower Universitas Mercu Buana Lantai 5 Dan,” pp. 246254, 2009.

[3] T. D. P. dan N. Finahari, "Pengaruh Perubahan Temperatur Media Pendingin pada Direct Evaporative Cooler," vol. 3, 2011. 
Perencanaan Sistem Pendingin Udara Menggunakan Ceiling Duct Dengan Pengaturan Sistem

Vrv/F Pada Gedung Perkantoran 3 Lantai

[4] İ. Erdemir Kocagil and G. Koçlar Oral, "The effect of solar heat gain on climate responsive courtyard buildings," A/Z ITU J. Fac. Archit., vol. 13, no. 2, pp. 39-46, 2016, doi: 10.5505/itujfa.2016.93898.

[5] ASHRAE, "ASHRAE Handbook Fundamentals and Data Book," Am. Soc. Heating, Refrig. Air Cond. Eng., vol. 1, pp. 90-1, 1997.

[6] I. Kharagpur, "Cooling and heating load calculations - esttimation of required cooling/heating," pp. 1-21, 2010, [Online]. Available: https://nptel.ac.in/courses/112105129/35.

[7] G. Solomon and Y. A. Adde, "Analytical Method To Calculate Room Cooling Load," Int. J. Eng. Technol. Manag. Res., vol. 7, no. 8, pp. 56-64, 2020, doi: 10.29121/ijetmr.v7.i8.2020.761.

[8] J. C. L. Danny H. WLi, "Solar heat gain factors and the implications to building designs in subtropical regions," Energy Build., vol. 32, no. 1, pp. 47-55, 2000, doi: https://doi.org/10.1016/S0378-7788(99)00035-3.

[9] B. L. Ahn, C. Y. Jang, S. B. Leigh, and H. Jeong, "Analysis of the effect of artificial lighting on heating and cooling energy in commercial buildings," Energy Procedia, vol. 61, pp. 928932, 2014, doi: 10.1016/j.egypro.2014.11.997.

[10] D. P. Putra and M. F. Hidayat, "Perencanaan Tata Udara Sistem Ducting Ruang Aula Lantai 8 Universitas 17 Agustus 1945 Jakarta,” J. Kaji. Tek. Mesin, vol. 2, no. 1, pp. 61-66, 2017. 